\title{
Application of Situational Simulation Teaching Method in Leadership Science and Art Course
}

\author{
Wang Hongmei ${ }^{1}$, Ning Xiaohua ${ }^{2,}$, , Sun Jing ${ }^{1}$, Pan Yunjia ${ }^{1}$, Xing Hua ${ }^{1}$ \\ ${ }^{1}$ School of Government Management, Central University of Finance and Economics, Beijing, China \\ ${ }^{2}$ Institute of Finance and Economics, Central University of Finance and Economics, Beijing, China
}

Email address:

wanghongmei@cufe.edu.cn (Wang Hongmei), ningxiaohua916@126.com (Ning Xiaohua), sunjingcufe@126.com (Sun Jing), 598987649@qq.com (Pan Yunjia), xingh_ruc@126.com (Xing Hua)

${ }^{*}$ Corresponding author

\section{To cite this article:}

Wang Hongmei, Ning Xiaohua, Sun Jing, Pan Yunjia, Xing Hua. Application of Situational Simulation Teaching Method in Leadership Science and Art Course. Teacher Education and Curriculum Studies. Vol. 5, No. 1, 2020, pp. 7-13. doi: 10.11648/j.tecs.20200501.12

Received: April 10, 2020; Accepted: April 27, 2020; Published: May 14, 2020

\begin{abstract}
Leadership science and art is a core course in management disciplines. Its goal is to cultivate students' leadership quality and management ability, with strong practicality, flexibility and artistry. Situational simulation teaching method has changed the limitations of traditional teaching method, such as teacher-centered, students' mechanical learning and lack of participation. Through situational creation, role playing, team cooperation, peer review and teaching feedback, it can effectively improve students' initiative, sense of substitution and team consciousness, and is suitable for leading science and art course teaching. Situational simulation teaching method includes three steps: pre-class preparation, class presentation and after-class summary. This paper introduces the design and implementation process of situational simulation teaching of leadership science and art based on the case of Nujiang hydropower development in China. Feedback from teaching activities shows that situational simulation teaching helps to improve students' comprehensive quality and increase students' satisfaction. The paper points out that the teaching effect of situational teaching method depends on careful pre-class preparation, class display and after-class summary. Teachers should play the role of "chief director" and guide and summarize in time.
\end{abstract}

Keywords: Situational Simulation, Leadership Science and Art, Teaching Method

\section{Introduction}

Traditional teaching method is a teaching method with the ultimate goal of imparting knowledge. It emphasizes the leading role of teachers and the systematic transmission of knowledge. It is a teacher-centered, knowledge-centered and class-centered teaching mode. There is no denying that this traditional teaching mode can directly, efficiently and mass impart knowledge and give full play to the leading role of teachers, which contributes to the rapid cultivation of knowledge-based and inherited talents. However, with the development of the times and the continuous changes of social needs, the limitations of traditional teaching methods in comprehensive quality education and innovative talents training, and in practical, flexible and artistic courses such as leadership science and art, are increasingly apparent [1].

\section{1. "Indoctrination" Teaching Mode of Students Learning Initiative is Insufficient}

The typical representatives of traditional teaching mode are Herbart's "transmission-reception teaching mode" and Kailov's "five-link teaching mode". Its greatest feature is the indoctrination of knowledge, while students are used as containers [2]. Under the traditional teaching mode, teachers are the center and main body of teaching activities, playing the role of knowledge giver while students are the passive recipients of knowledge. The whole teaching activity in the classroom is centered on teachers. Classroom teaching is basically about teachers' teaching, writing on the blackboard, students listening and taking notes. In the whole teaching process, the students are in a passive listening state, lacking 
participation and learning initiative. This indoctrination teaching mode seriously ignores students' autonomy, making students passively accept knowledge in a boring classroom atmosphere, and gradually forming the bad habit of relying on teachers, not asking questions, not thinking, not daring to question [3]. It is not conducive to stimulating the enthusiasm of students in learning and cultivating the spirit of active learning.

\subsection{The Lack of the Sense of Substitution in Cultivating Leaders' Thinking}

Leadership Science and Art is a practical, flexible and artistic course [4]. It is far from enough to rely only on teachers to spoon-feed basic theoretical knowledge for the cultivation of students' leadership thinking and the improvement of management ability [5]. The traditional teaching method focuses on teachers' teaching, that is, "teachers speak and students listen". Through rote learning and mechanical learning, students can only learn theoretical knowledge from books. However, there is a lack of in-depth understanding of knowledge, what kind of knowledge to use in what situation and how to use knowledge to solve practical problems. In addition, the traditional teaching method lacks teacher-student interaction and students' participation in the whole teaching process. The teaching mode of "emphasizing theory and neglecting practice" and "emphasizing teaching and neglecting participation" lacks leadership situations, which makes it difficult for students to personally experience and seriously lacks the sense of substitution in cultivating students' leadership thinking [6].

\subsection{The Lack of Training Students' Sense of Teamwork}

The traditional teaching method is "knowledge-based" rather than "student-based" teaching, and students have become containers for receiving knowledge, rather than life subjects with personality, thus losing the overall care for all-round development. Traditional teaching methods are single, and "three ones" (a textbook, a blackboard and a piece of chalk) run through the whole teaching activity all the time. In addition, students' dominant position in learning has been neglected, resulting in teachers "solo" in the whole teaching process, and students can only become independent "audiences". In the whole teaching activities, students are often listeners, passively accepting one-way knowledge transmission and lacking a two-way interactive simulation practice platform. The two-way interaction here is not only the interaction between teachers and students, but also the interaction between students. This kind of practical interaction is an important cornerstone to cultivate students' team cooperation consciousness, and traditional teaching method is precisely due to the lack of this kind of two-way interaction, resulting in insufficient cultivation of students' team cooperation consciousness [7].

\section{The Advantages of Situational Simulation Teaching Method in Applying Leadership Science and Art Courses}

Situational simulation teaching method refers to that teachers combine theory with practice, "teaching" and "learning" by creating simulation situations, and "teaching" and "learning" are mutually dependent to form a viable classroom system, thus forming a student-oriented classroom teaching with humanistic care [8]. It has a high degree of practicality and two-way interaction that traditional teaching methods cannot achieve. This kind of experience teaching method can enable students to be personally present and strengthen students' sense of substitution; Fully mobilize the enthusiasm, initiative and creativity of students; Let students cultivate cooperation consciousness and team spirit in team participation. This is the strong advantage of situational simulation teaching method in the application of leadership science and art courses.

\subsection{Role-playing, to Mobilize the Initiative of Students}

Situational simulation teaching activities are generally carried out through role playing. Teachers create simulated real scenes by selecting real situational materials that match the teaching content, create a real environment atmosphere, and then let students play different roles in the situation. Different from the traditional teaching method, situational simulation teaching method focuses on students, and the whole teaching process revolves around students and focuses on students' participation, highlighting students' dominant position. The creation of situations and the roleplaying enable students to participate in teaching activities throughout the process and to carry out multi-dimensional interactive learning, thus greatly improving students' participation [9]. This practical, interactive and comprehensive teaching method is very lively and interesting, which can fully stimulate the enthusiasm of students and effectively mobilize their autonomy in learning.

\subsection{Immersive, to Strengthen Students' Sense of Substitution}

Situational simulation teaching method is different from traditional teaching method, it is a typical personal experience teaching method. Based on a possible event in reality, teachers use props to create a situational environment and carry out a high degree of simulation to move scenes that only occur in reality to the classroom, providing a practical platform for students. In this near-real environment, through role-playing, students will be personally present and their sense of learning will be strengthened [10]. Through personal participation and experience, students can substitute the theoretical knowledge they have learned into practice for testing, thus 
deepening their understanding and application of theoretical knowledge [11]. This immersive sense of substitution is an important medium to deepen students' understanding of the theoretical knowledge of leadership science and cultivate students' leadership thinking. It is also the advantage of situational simulation teaching method applied to leadership science and art courses.

\subsection{Team Participation, to Train Students' Sense of Cooperation}

Situational simulation teaching abandons the one-way transmission of knowledge in traditional teaching and focuses on two-way interaction, which includes interactive cooperation among students. In the situational simulation teaching activities, the students are divided into several groups, and each group member carries out division of labor and cooperation to play its own role. In the preparation process of the exercise, the team members cooperate and work together to complete the teaching task, communicate with each other, understand each other and cooperate with each other, and to realize the teaching goal. This process makes students feel the sense of collective honor, improves the students' team consciousness and cooperation consciousness, and enhances the students' cooperation spirit and tacit understanding [12]. Situational simulation teaching method is practical and interactive, which gives students the opportunity to participate in teaching activities, provides a platform for team participation, and provides an effective way to cultivate students' cooperative consciousness and team spirit.

\section{General Process of Situational Simulation Teaching Method}

Situational simulation teaching method includes many specific forms, including role-playing, non-leading group discussion, conversation, management games, etc. However, its operation process is generally divided into three stages, including three steps [13]: preparation before class, class presentation and after-class summary. As shown in figure 1.

\begin{tabular}{|c|c|c|}
\hline Pre-class preparation & Classroom display & After-class summary \\
\hline Teacher preparation: & Teacher: & Students: \\
\hline $\begin{array}{l}\text { * Clear teaching } \\
\text { content and goals }\end{array}$ & $\begin{array}{l}\text { * Organize classroom } \\
\text { display and maintain order }\end{array}$ & $\begin{array}{l}\text { * Students discuss and } \\
\text { exchange feelings with each other }\end{array}$ \\
\hline * Design simulation scenarios & * Time & * Students evaluate the teaching effect \\
\hline * Design score sheet & * Record score & * Student feedback and suggestions \\
\hline * Compose task book & * Consultation and guidance & $\begin{array}{l}\text { * Insufficient writing experience } \\
\text { and self-summary }\end{array}$ \\
\hline \multicolumn{3}{|l|}{ * Describe and post tasks } \\
\hline \multirow[t]{2}{*}{ * Group students } & students: & Teacher: \\
\hline & * Do presentation in group order & $\begin{array}{l}\text { * Comment on the entire process } \\
\text { and student performance, pointing } \\
\text { out the good aspects and areas for improvement. }\end{array}$ \\
\hline Student preparation: & $\begin{array}{l}\text { * Introduction background } \\
\text { and role assignment }\end{array}$ & \multirow{2}{*}{$\begin{array}{l}\text { * A comprehensive summary of the } \\
\text { entire presentation process, student } \\
\text { performance, teaching effectiveness, } \\
\text { student feedback, etc. }\end{array}$} \\
\hline * Theoretical knowledge preparation & $\begin{array}{l}\text { * Seriously demonstrating } \\
\text { your character }\end{array}$ & \\
\hline * Situation and character analysis & & \multirow{2}{*}{$\begin{array}{l}\text { * Identify the shortcomings of } \\
\text { each link and seek ways to } \\
\text { improve and perfect it. }\end{array}$} \\
\hline $\begin{array}{l}\text { * Assignment of roles } \\
\text { within the group }\end{array}$ & Students to be shown: & \\
\hline * Line preparation & * Prepare for presentation on stage & \\
\hline * Pre-drill & $\begin{array}{l}\text { * Score the display team according } \\
\text { to the rating table }\end{array}$ & \\
\hline
\end{tabular}

Figure 1. General process of situational simulation teaching method.

\subsection{Preparation Before Class}

\subsubsection{Teacher Preparation}

According to the teaching objectives and teaching contents, teachers design simulated situations that match the teaching contents. According to the investigation content, the scoring index is designed and the scoring table is made. Simulate the teaching process based on the whole situation and write the task book. Explain the task and process of situation simulation to the students and issue the task book. Finally, divide the students into groups and form a team.

\subsubsection{Students Preparation}

After understanding the simulated situation task, the 
students combine the teaching contents and objectives to prepare the basic theoretical knowledge. Analyze the background and role of the situation and assign roles in the group. All the role players coordinate with each other and prepare their own lines. Carry out the pre-exercise before the class presentation, so that the whole demonstration process can proceed smoothly.

\subsection{Classroom Display}

\subsubsection{The Role of Teacher}

Organize teaching activities to maintain good classroom order. Let the students show on stage one by one according to the group order and time them. During each group of presentations, key nodes and students' performance were recorded and scored accordingly. In addition, to control the whole process, do a good job of consultation and guidance.

\subsubsection{Role Interpretation}

The students on the stage pay attention to their group order and get ready to play in advance. When performing on stage, the group leader will first brief everyone on the background and the roles played by each member. After that, all the role players should devote themselves to their roles and try their best to achieve the best performance.

\subsubsection{Peer Evaluation}

Students to be shown should pay close attention to their playing sequence and be ready to play at any time. In addition, students who carefully watched the demonstration on stage were graded according to their performance, such as words and deeds, knowledge application, overall effect, etc., and the deficiencies and outstanding points were recorded.

\subsection{Summary After Class}

\subsubsection{Students' Feedback}

After the class presentation, students' feedback information should be collected in time. Let the students discuss with each other and exchange their feelings. And to evaluate the effect of this teaching activity, and put forward their own opinions and suggestions. According to the whole process and self-expression, write the experience, summarize the deficiencies and submit PPT case report.

\subsubsection{Teacher's Comments}

According to the students' performance in class, comment on each group and point out the aspects of each group's good performance and the areas for improvement. Based on the students' feedback, opinions and suggestions, enthusiasm for participation, teaching effect, etc., a comprehensive summary of the whole situation simulation teaching process is carried out to find out the shortcomings of each link and find out the improvement methods.

\section{Application of Situational Simulation Teaching Method: Based on the Case of "Nujiang River Hydropower Development" in China}

\subsection{Case Scenario Description}

Nujiang River is one of the major rivers in southwest China, also known as Lujiang River. It originates from Gyerepatagi at the southern foot of Tanggula Mountain on the Qinghai-Tibet Plateau. It goes deep into the QinghaiTibet Plateau, from northwest to southeast of the First Gulf of Nujiang River, obliquely crosses the flat shallow valley in eastern Tibet, flows southward into Yunnan Province, passes through Nujiang Lisu Autonomous Prefecture, Baoshan City and dehong autonomous prefecture, flows into Myanmar, is renamed salween, and finally flows into the Andaman Sea in the Indian Ocean. The middle and lower reaches of the Nujiang River, with abundant and stable runoff, large drop, convenient transportation and good development conditions, are rich in hydropower resources and have better development conditions. They are also one of China's hydropower energy bases yet to be developed. Since 2003, due to serious disputes between ecological environment protection and hydropower development, Nujiang River hydropower development has become the focus of attention from the outside world, triggering a fierce debate on the issues of "construction" and "prudent construction".

Based on the background of the case, it is assumed that the Yunnan provincial government will hold a "symposium on hydropower development in the Nujiang river basin", in which all students will play roles and simulate the exchange process of the symposium.

\subsection{The Situation Simulation Process}

\subsubsection{Preparation Before Class}

(1). Case materials and situation design

The teaching content of this course is leadership art, and the selected case materials are derived from the real events in China's reality and conform to the teaching content and students' actual life. The situation is set in the form of a symposium. Movable desks and chairs in the classroom can be used to create a live atmosphere for the symposium, enhance students' sense of substitution and stimulate students' interest in participation.

(2). Role setting

The role setting of the "Symposium on Hydropower Development in Nujiang River Basin" includes government officials, non-governmental environmentalists, experts supporting hydropower development, experts opposing hydropower development, hydropower development companies and local villagers. The role setting is reasonable and each is closely related to life. The viewpoints and positions of each role are shown in Table 1: 
Table 1. Position of Various Roles in Symposium on Hydropower Development in Nujiang River Basin."

\begin{tabular}{|c|c|c|}
\hline Serial number & Role & Role position \\
\hline 1 & Government officials & $\begin{array}{l}\text { The environment needs protection and the economy needs development. Listen to the } \\
\text { opinions of all parties, maintain order, take over the overall situation and coordinate } \\
\text { all parties [14]. }\end{array}$ \\
\hline 2 & Private environmentalists & Opposition to Nujiang Hydropower Development or Careful Development (option 1) \\
\hline 3 & Experts supporting hydropower development & Support Nujiang Hydropower Development \\
\hline 4 & Experts Opposing Hydropower Development & Oppose Nujiang Hydropower Development \\
\hline 5 & Hydropower Development Corporation & Support Nujiang Hydropower Development \\
\hline
\end{tabular}

(3). "Scoring Form" and "Feedback Form for Teaching Activities" Design

The content of this teaching is leadership art, and the teaching goal is to enable students to master the basic theoretical knowledge of leadership art, including the art of leadership motivation, the art of leadership language and the art of leadership balance, and to cultivate students' leadership thinking and management ability. According to the teaching content and objectives, as well as the cultivation of students' comprehensive quality, and considering the teaching effect and other factors, the scoring index is designed, including the mastery degree of basic theoretical knowledge, language expression, thinking and cutting-in points, team cooperation, overall display effect, etc. Feedback indicators of students' teaching activities include deepening their understanding and mastery of theoretical knowledge, stimulating their interest and enthusiasm in learning, strengthening their ability to analyze and deal with problems, enhancing their team cooperation ability, stimulating their initiative and creativity, cultivating leaders' thinking and application ability, and overall teaching satisfaction, etc. Among them, the "scoring table" is shown in Table 2, and the "teaching activity feedback table" is shown in Table 3.

Table 2. Scoring Table.

\begin{tabular}{l}
\hline Leadership Science and Art Course Group ( ) \\
record the key points in the show process \\
Scoring Index (20 points for each item) \\
Degree of mastery of basic theoretical \\
knowledge \\
Language expression \\
Thinking to Cut to the Point \\
Team collaboration \\
Overall display effect \\
Total
\end{tabular}

Table 3. Feedback Form of Teaching Activities.

\begin{tabular}{l} 
Leadership Science and Art Situation Simulation Teaching Effect \\
Feedback Form \\
\hline Indicators (10 points per item) \\
Deepen the understanding and mastery of theoretical knowledge \\
Stimulate interest and enthusiasm in learning \\
Strengthen the ability to analyze and deal with problems \\
Enhance team cooperation ability \\
Stimulate initiative and creativity \\
Cultivating Leaders' Thinking and Application Ability \\
Overall teaching satisfaction \\
Comments and suggestions \\
\hline
\end{tabular}

\section{(4). Task distribution}

Provide students with case materials, explain the case situation, and explain the role. Divide the class of 30 people into five groups, and each group will show for no more than 30 minutes. Appoint a team leader. Each team will collect materials, assign roles, prepare lines, rehearse in advance, and make careful and sufficient preparations under the leadership of the team leader.

\subsubsection{Situational Simulation}

Use classroom activity tables and chairs to arrange the forum situation in advance, distribute the scoring forms, and reserve three minutes for each group to show up on stage. Then each group will take the stage one by one according to the sequence. Before each group shows, they will explain their respective roles, devote themselves to the situation, give full play to their creativity and imagination according to their understanding of the roles, and deduce their own achievements. Other students watched carefully, and recorded and scored according to the scoring table. At the same time, they were ready to show on stage. Teachers record and grade students' presentations to prepare for comments and summaries, and at the same time maintain good classroom order and control time so that situational simulation teaching activities can be carried out in an orderly manner.

\subsubsection{Summary and Evaluation}

After each group's situational presentation is completed, summary and evaluation shall be conducted in a timely manner. First of all, the situation simulation case of "Nujiang River Basin Hydropower Development Symposium" is analyzed. The characteristics of each role are analyzed. The connection between the case and the teaching content of the course is explored. The students' thinking is diffused and triggered. Then comment on the presentation process of each group, point out the advantages and disadvantages, affirm and encourage their performance, and put forward suggestions for improvement. Secondly, guide students to discuss and communicate with each other and deepen their understanding of the theoretical knowledge of leadership art; Students reflect on and summarize their personal performance. Feedback the situation design, teaching effect, learning effect and acceptance degree, and fill in the feedback form for submitting teaching activities.

The biggest problem in this exhibition was that some groups were too involved, which led to emotional and heated 
debates. However, through timely intervention, the scene was effectively prevented from getting out of control. This shows that some students need to improve their language communication and emotional control, and their understanding and application of the theoretical knowledge of leadership language, balance and motivation art are not in place. Based on the whole teaching process, students' enthusiasm for participation and feedback, it is believed that the situation simulation teaching has a good effect. The scores of each index in the feedback form of teaching activities are above 8 . The students have a deeper understanding and experience of the theoretical knowledge of leadership art, which is conducive to the cultivation of students' comprehensive quality ability. In addition, the teaching form is interesting, lively, students' enthusiasm for participation is high, and their satisfaction is high.

\section{Conclusion}

Tao Xingzhi, a famous educator in China, said: "I think a good teacher is not teaching, not teaching students, but teaching students to learn."Leadership science and art is an applied course, and practice is the source of its vitality. Many years of teaching practice show that situational simulation teaching method has realized the combination of theory and practice, and the combination of "teaching" and "learning" can not only enable students to understand and master the theoretical knowledge of leadership science and art courses, but also cultivate students' leadership thinking and management ability. In the process of applying situational simulation teaching method to leadership science and art courses, we should pay attention to the following points:

\subsection{Pre-class Preparation of Situational Simulation Teaching Method}

The premise of applying situational simulation teaching method is that the teaching content can be contextualized, and the higher the contextualization degree, the better the teaching effect [15]. Therefore, in applying situational simulation teaching method to leadership science and art courses, it is first necessary to judge whether the teaching content in leadership science and art courses is suitable for contextualization, to seek truth from facts, and not to contextualize for contextualization. The second is the choice of scenario simulation cases and the design of scenarios. The quality of case materials and situational design is the basis for the situational simulation teaching method to achieve good teaching results. The selection of cases should pay attention to the following aspects: first, teachers should strictly follow the teaching contents and teaching objectives, and the selected cases should be compatible with them; The second is that the cases are best from real events related to leadership activities in life, close to the reality that students can understand. Third, case selection should be feasible, in line with the level of students, with moderate difficulty, to ensure the completion of classroom time; Fourth, cases should be flexible and open, so that students have room to think and can cut in from different angles and levels to fully stimulate students' creativity. The situation design should pay attention to the following aspects: First, according to the teaching content and case materials, reasonably design the situation and role; Situational design should be real, close to life and in line with reality. Second, the situation design should be interesting and can stimulate students' interest and enthusiasm. The third is that the link of situation design should be as detailed, thorough and coherent as possible. Finally, we should pay attention to the task distribution and guide students to prepare carefully to avoid students' understanding errors. We should explain it to students in detail to ensure that each student fully understands the specific information such as the goal, content, process and matters needing attention of situational simulation, so that students can make full preparations towards the goal of situational teaching [16].

\subsection{Classroom Display of Situation Simulation Teaching Method}

Situational simulation demonstration is the key stage of the implementation of situational teaching method and the core process of teaching activities. Students are the leading role in the classroom display. Their input level, performance level and participation attitude are important factors that affect the display effect, and are related to whether situational teaching method can achieve good teaching effect and whether the teaching goal can be realized. Therefore, before class display, students should be encouraged to participate seriously, devote themselves to role playing, demonstrate their understanding of the role, give full play to their creativity, and show their talent and level. Classroom display is a student-led stage, and students are the "leading role". However, it should be noted that teachers are the "chief director" of the whole situation simulation process, and their role is also very important. Teachers cannot ignore the display process and should guide it in due time, which is related to the smooth development of the whole teaching process. Specifically, we should pay attention to the following points: First, maintain good classroom discipline, control the time, and make the classroom display orderly; The second is to pay attention to observation, understand the students' understanding and mastery of the content of leadership science and art courses, and record the advantages and disadvantages exposed by the students' performance, so as to lay the foundation for the following comments. Third, the student's presentation process must be complete and cannot be interrupted at will in order to avoid affecting the student's thinking and performance. Fourth, teachers should not rush to comment after each group presentation, and comment after all the group presentations, so as not to influence the subsequent group presentations. Fifth, students to be displayed should record the performance of the display group in the process of participation, prepare for the following communication and discussion, and let students learn from each other and learn from each other through peer learning. 


\subsection{After-class Summary of Situational Simulation Teaching Method}

After-class summary is the last link of situational simulation teaching method and an indispensable "process". In order to evaluate the teaching effect, analyze the problems, solve the problems, deepen the theoretical knowledge study of leadership science and art courses, and summarize the practical experience, an interactive exchange platform is provided. It is an important guarantee to continuously improve the situational simulation teaching method and improve the teaching quality. After the demonstration of the situational simulation class, the teacher should discuss and summarize the whole teaching process in time. One is to analyze the whole situation simulation case, pointing out the theoretical knowledge and problems related to leadership science and art involved in the case, spreading students' thinking and triggering students' thinking. Comment on each group, point out their advantages and disadvantages, affirm and encourage their efforts, and put forward suggestions for improvement. The second is to guide students to discuss and communicate with each other, deepen their understanding of the theoretical knowledge they have learned, consolidate what they have learned, and guide students to self-reflect and summarize their personal performance. Feedback the situation design, teaching effect, learning effect and acceptance degree, and put forward their own opinions and suggestions. Third, teachers should summarize the whole situation simulation teaching process, make an overall evaluation on whether the case materials are suitable for the teaching content, the overall teaching effect and the completion of the teaching objectives, analyze the problems existing in the whole process, sum up experience, and adjust and optimize the situation simulation teaching in combination with students' participation enthusiasm, performance, feedback opinions and suggestions, so as to make it more in line with students' learning rules and learning conditions, so that students can have a deeper understanding and mastery of theoretical knowledge, exercise practical ability and improve comprehensive quality through the situation simulation teaching method.

\section{Acknowledgements}

This research was supported by the project "Application of Scenario Simulation Technology in Practical Teaching of Public Management and Construction of Characteristic Curriculum System" which was funded by the Education and Teaching Reform Fund of the Central University of Finance and Economics in 2012.

\section{References}

[1] Leadership: Perspectives in Theory and Research. Arthur G. Jago. Management Science. 1982 (3).

[2] Liu Jian. Situational Simulation Teaching in Strategic Management Curriculum Application. China Science and Education Innovation Guide, No. 10, 2009, pp. 30-31.

[3] Brown JS, Collins A, Duguid P. Situated cognition and the culture of learning. Educational Research. 1989.

[4] William A. Cohen. The Art of Leadership. Guangming Daily Press, 2001.

[5] Ken Shelton. What is leadership. Shanghai People 's Publishing House, 2000.

[6] Zhang Guobao, Jiao Lixin. Exploration on the Application of Situational Simulation Teaching Method in Marketing Major Courses. Higher Agricultural Education, No. 2, 2010, pp. 6264.

[7] Yuan Yinzhi. On the "scenario simulation" in the "tour guide business" course teaching application. Wuhan Institute of Business Services, No. 3, 2009, pp. 63-65.

[8] Rahat Iqbal, Peter Every. Scenario based Method for Teaching, Learning and Assessment. Conference On Information Technology Education: Proceedings of the 6th conference on Information technology education, Oct. 2005.

[9] Debriefing 101: Training Faculty to Promote Learning in Simulation-based Training. John T. Paige, Sonal Arora, Gladys Fernandez, Neal Seymour. The American Journal of Surgery. 2014.

[10] Chang Xin. Application of Situational Simulation Teaching Method in International Business Negotiation Course. Contemporary Economy, No. 5, 2009, pp. 122-123.

[11] Ding Ning. Functional Orientation and Realization of Situational Simulation Teaching Mode [J]. Higher Education Exploration, No. 2, 2018, pp. 47-51.

[12] Liu Yuxin. The application of simulated scene teaching method in the course of "On-site First Aid". Journal of Anhui Vocational College of Police Officers, No. 6, 2009, pp. 81-82.

[13] Hou Erxiu. Research on the Application of Situational Simulation Teaching Method in Organizational Behavior Course. Journal of Inner Mongolia University of Technology, No. 2, 2009, pp. 91-93.

[14] Debra Benton. The Charm of Leaders. China Financial and Economic Publishing House, 2004.

[15] Liu Xueming. Application of Scenario Simulation Method in Public Policy Teaching. Education Review, No. 1, 2011, pp. 95-97.

[16] Wang Qingzhong. Situational Teaching Method in Ideological and Political Course Theory Constructio 25-27. 